\title{
Associations of killer cell immunoglobulin- like receptor genes with rheumatoid arthritis
}

\author{
S. Ramírez-De los Santos ${ }^{\mathrm{a}, \mathrm{b}}$, P.E. Sánchez-Hernández ${ }^{\mathrm{a}}$, J.F. Muñoz-Vallec ${ }^{\mathrm{c}}$ C.A. Palafox-Sánchez ${ }^{\mathrm{c}}$, \\ L.Y. Rosales-Rivera ${ }^{a, b}$, T. García-Iglesias ${ }^{\mathrm{a}}$, A. Daneri-Navarro ${ }^{\mathrm{a}}$ and M.G. Ramírez-Dueñas ${ }^{\mathrm{a}, *}$ \\ ${ }^{a}$ Laboratorio de Inmunología, Departamento de Fisiología, Centro Universitario de Ciencias de la Salud, \\ Universidad de Guadalajara, Guadalajara, Jalisco, México \\ ${ }^{\mathrm{b}}$ Doctorado en Ciencias Biomédicas, Departamento de Fisiología, Centro Universitario de Ciencias de la Salud, \\ Universidad de Guadalajara, Guadalajara, Jalisco, México \\ ${ }^{\mathrm{c}}$ Departamento de Biología Molecular y Genómica, Centro Universitario de Ciencias de la Salud, Universidad de \\ Guadalajara, Guadalajara, Jalisco, México
}

\begin{abstract}
Objective: Rheumatoid Arthritis (RA) is an autoimmune and chronic inflammatory disease of unknown etiology. Killer cell immunoglobulin-like receptors are expressed on the surface of natural killer cells and CD28null T-cells, both present in synovial membrane of RA. Therefore we evaluated the associations of KIR genes with RA.

Methods: 16 KIR genes were genotyped in 100 healthy subjects (HS) and 100 RA patients from Western Mexico using PCR-SSP. Differences in KIR genotypes and gene frequencies were assessed using the $X^{2}$ test.

Results: Gene frequency of KIR2DL3 was lower in RA than in HS $(p=0.0019)$, whereas KIR2DL2 and KIR2DS2 were higher in RA than HS ( $p=0.0004$ and $p=0.0487$, respectively). In addition were identified 38 genotypes (from G1-G38) in both studied groups, and the genotype frequencies of G1, G6 and G14 showed significant differences $(p=0.0001, p=0.0208$ and $p=0.0300$, respectively).

Conclusions: The presence of KIR2DL2, KIR2DS2 and absence of KIR2DL3 are associated with RA. Moreover, two genotypes $\mathrm{BX}$ are associated with RA. These results suggest that KIRs can be involved in RA susceptibility.
\end{abstract}

Keywords: KIR, killer cell immunoglobulin-like receptor, CD158, natural killer cell receptors, rheumatoid arthritis, autoimmune disease

\section{Introduction}

Rheumatoid Arthritis (RA) is a chronic inflammatory autoimmune disease, affecting about $1 \%$ of the world population [1]. RA is considered a clinical syndrome spanning several disease subsets, where the main clinical manifestation is the formation of proliferative pannus which triggers persistent synovitis, damage and the loss of function in the diarthrodial joints $[1,2]$.

The etiologic factors to RA vary from one population to another, in which the initiator agents and the environ-

*Corresponding author: María Guadalupe Ramírez Dueñas, Laboratorio de Inmunología. Departamento de Fisiología. Centro Universitario de Ciencias de la Salud. Universidad de Guadalajara. Calle Sierra Mojada No. 950, Colonia Independencia, Guadalajara, Jalisco, C.P. 44340. México. Tel.: +52 33105853 07; E-mail: mgramirezd@gmail.com. ment acting on genetically susceptible subjects [3,4]. The genetic contribution to RA susceptibility has been estimated to present about $60 \%$ [4], where certain alleles of $H L A-D R B 1$ gene have been considered the major genetic risk factor [5]. However, the etiologic fraction of HLA-DRB1 locus accounts for only $30 \%$ of genetic susceptibility. This indicates that different genes to those of $H L A-D R$ are also involved in the susceptibility to disease $[4,5]$.

The killer cell immunoglobulin-like receptors gene cluster has generated great interest due to its complex genetic variability which cause a high degree of KIR heterogeneity between individuals, besides that has been previously implicated in inflammatory and autoimmune conditions [6]. The KIR gene cluster spans approximately $150 \mathrm{~kb}$ in the leukocyte receptor complex located on chromosome 19q13.4 [7]. 
The KIRs (CD158 family) are a group of genetically variable membrane proteins involved in immune function of the natural killer cells and CD28null T-cells, both present in synovial membrane of RA [8]. Reduced blood CD56 dim NK cells activity has been shown to occur in patients with RA, on the other hand CD56bright NK cells have been shown to accumulate in the synovial fluid producing large quantities of IFN- $\gamma$ contributing to the inflammatory environment characteristic of the disease [9].

CD28null T-cells are expanded in RA, these cells produce large amounts of IFN- $\gamma$, and express granzyme $\mathrm{B}$ and perforin, giving them the capability to lyses target cells and cause damage to tissue $[8,10]$. They tend to preferentially and even exclusively display KIR activating receptors as KIR2DS2 which could play role as co-stimulatory molecule. KIR2DS2 T-cell clones are frequently observed on RA patients with vascular complications $[8,10]$.

The effector activity of these cells is determined by the activator/inhibitor balance of KIR receptors and their interaction with HLA class I. The major ligands for inhibitory KIRs are HLA-C molecules [7]. There are many allelic variants of $H L A-C$ but in terms of KIR recognition these can be reduced in two groups: HLA$\mathrm{C} 1$ molecules (characterized by asparagine at position 80) are recognized by inhibitory KIRs: KIR2DL2 and KIR2DL3, whereas HLA-C2 molecules (characterized by lysine at position 80) are recognized by KIR2DL1 [7, 11]. The KIR2DS2, KIR2DS3 and KIR2DS1 are activating KIRs and almost identical to the inhibitory KIRs counterpart in sequence but have a lower affinity for HLA-C, suggesting that these class I molecules may not be the major ligands of activating KIRs [7,12].

The KIR genotypes exhibit differences at two levels of variability: the structural level (KIR gene content, presence/absence) and the allelic level (between alleles of KIR genes contained) [6]. Nomenclature [13] for $K I R$ genotypes include: AA genotype (predominantly inhibitor) in which must be absent genes: KIR2DL2, KIR2DL5, KIR3DS1, KIR2DS1, KIR2DS2, KIR2DS3, KIR2DS5; and BX genotype (predominantly activator) when at least one of them is present. Thus the major functional distinction between the two groups of genotypes $\mathrm{AA}$ and $\mathrm{BX}$ is the number of activating KIRS genes [13].

Expression analysis of KIR genes reveals that different clones of NK cell and CD28null T-cells in a particular individual express different combinations of KIRs encoded within their genome [7,14]. The KIR molecules have been considered potentially important in susceptibility to infection and polygenic disorders such as autoimmunity [12].

Associations of KIR genes: KIR2DL2, KIR2DS2, KIR3DS1 and KIR2DS4 with RA have been demonstrated in Caucasian [10], Polish [15] and Taiwanese [16] populations. Here, we examined whether $K I R$ genes could be associated with RA in the western Mexico population.

\section{Subjects, materials and methods}

\subsection{Subjects}

A total of 100 RA patients classified by a physician rheumatologist according to the American College of Rheumatology and European League Against Rheumatism (ACR-EULAR) criteria [17] were enrolled in the study. The RA patients were recruited from the Rheumatology Department of The Hospital General de Occidente, Jalisco, Mexico. As a controls group, we recruited 100 healthy subjects (HS). The RA patients and HS were born in western Mexico comprising the states of: Jalisco, Nayarit, Colima, Aguascalientes, Guanajuato, Michoacan and Zacatecas, as well as similar genetic background and a family history of Mexican ancestors, at least back to the third generation. Informed consent was obtained from both study groups. The committee of biosecurity and ethics of Centro Universitario de Ciencias de la Salud of Universidad de Guadalajara approved the present study in compliance with The Code of Ethics of the World Medical Association (Declaration of Helsinki, Korea 2008).

\subsection{DNA extraction}

Genomic DNA was isolated from peripheral blood leucocytes using procedures described previously [18]. Briefly, it comprised precipitation with $\mathrm{NaCl}$ saturated salts from leukocytes contained in $5 \mathrm{~mL}$ of venous blood with ethylene diamine tetra-acetic acid as an anticoagulant. DNA was then precipitated in absolute ethanol, dissolved in distilled and sterile water and store at $-20^{\circ} \mathrm{C}$ until analysis.

\subsection{KIR genotyping by PCR-SSP}

PCR-SSP (Polymerase Chain Reaction with specificsequence primers) was performed in a total reac- 
Table 1

Demographic and clinical characteristics of RA patients and HS

\begin{tabular}{lcc}
\hline Characteristics & RA & $n=100$ \\
& $n=100$ & \\
Demographic & $48 \pm 14(18-83)$ & $43 \pm 11(18-74)$ \\
Age, years (range) & $89 / 11$ & $89 / 11$ \\
Sex (F/M) & \\
Clinical & $87 \%$ & $0 \%$ \\
Anti-CCP positive ( $>5$ U/mL ) & $57 \%$ & $18 \%$ \\
Family history of autoimmunity & $9.0 \pm 8.9(0.3-40)$ & NA \\
Disease duration, years (range) & \\
\hline
\end{tabular}

Values represent the mean, minimum and maximum range; some of them represent percentage; RA rheumatoid arthritis; Family history of autoimmunity: Family related autoimmune disease of first and second degree of consanguinity; Anti-CCP: Anti-Cyclic Citrullinated Peptide antibodies; NA: Not Applicable.

tion volume of $20 \mu \mathrm{L}$, consisting of $4 \mu \mathrm{L}$ of DNA, $10 \mu \mathrm{L}$ of BioMix Red 10X (Bioline ${ }^{\circledR}$ ) and volume rest of primers solution. For the amplification were used specific-sequence primers [19], genotyping allow to identify presence or absence (by direct count) of $16 K I R$ genes in each subject and the identification of the allele KIR2DS4*001. All amplified products were resolved on a $3.0 \%$ agarose gel in buffer TBE $1 \mathrm{X}$ Ultrapure (Invitrogen ${ }^{\circledR}$ ), stained with solution Syber Safe (Invitrogen ${ }^{\circledR}$ ), 30 minutes in dark conditions and photographed with Molecular Imaging Software V5.X $\left(\operatorname{Kodak}^{\circledR}\right)$.

\subsection{Statistical analysis}

Associations with specific KIR genes, KIR genotypes and gene combinations were tested using the chi squared $\left(X^{2}\right)$ test considered Yates correction when necessary and were statistically significant when $p<$ 0.05. For this purpose we used the Epidat V3.1 statistical software.

\section{Results}

\subsection{Subjects characteristics}

The main demographic and clinical characteristics of RA patients were: 89 female, 11 male; mean age $48 \pm 14$, range: $18-83$ years; $87 \%$ with Cyclic Citrullinated Peptide antibodies (anti-CCP) positive and average disease duration of 9.0 years, range $0.3-40$. All patients were classified according to ACR-EULAR 2010 criteria, and were treated with disease modifying antirheumatic drugs (DMARDs) and/or non-steroidal anti-inflammatory drugs (NSAIDs). The main characteristics of HS were: 89 female, 11 male; mean age $43 \pm 11$ years, range 18-74; and $0 \%$ with CCP antibodies positive. Full details of both groups of study are shown in Table 1.

\subsection{Gene frequencies}

The genes frequencies of KIR2DL3, KIR $2 D L 2$ and KIR2DS2 show significantly differences. The $K I R 2 D L 3$ gene was distributed less frequently in RA ( $p=0.0019, O R=0.213)$; whereas the gene frequencies of $K I R 2 D L 2$ and KIR2DS2 were significantly higher in RA patients $(p=0.0004, O R=2.819$ and $p=$ $0.0487, O R=1.750$, respectively).

The frame genes: KIR2DL4, KIR3DL2, KIR $3 D L 3$ and $K I R 3 D P I$ were virtually present in $100 \%$ of RA patients and HS. KIR2DPl pseudogene was present in $97 \%$ of RA patients and $98 \%$ of HS. The rest of gene frequencies: KIR3DL1, KIR2DL1, KIR2DS4, KIR2DL5, KIR3DS1, KIR2DS1 and KIR2DS3 were different in both groups without show significant differences. Full details of all gene frequencies are shown in Table 2.

\subsection{AA and BX genotypes groups frequencies}

KIR genotypes were classified as AA (predominantly inhibitor) and BX (predominantly activator). The frequency of AA group was decreased in RA compared with HS ( $p=0.0171, O R=0.461)$, whereas BX group was significantly increased in RA patients $(p=0.0171$, $O R=2.168)($ see Table 3$)$.

\subsection{Genotype frequencies}

We analyzed the genes present in our study population and we found 38 genotypes (named as G1 to G38) identified and classified according with the Allele Frequency Database Net (ID number) [13]. Genotype frequencies of G6 and G14 in RA patients were significantly increased $(p=0.0208, O R=2.796$ and $p=0.0300, O R=6.887$, respectively). In contrast the genotype G1 frequency was increased significantly 
Table 2

Frequency of 16 KIR genes in RA patients and HS

\begin{tabular}{|c|c|c|c|c|c|}
\hline$K I R$ gene & $\mathrm{RA}(n=100) \%$ & $\mathrm{HS}(n=100) \%$ & $p$ & OR & $95 \% \mathrm{CI}$ \\
\hline $3 D L 1$ & 98 & 93 & NS & & \\
\hline $2 D L 1$ & 96 & 99 & NS & & \\
\hline $2 D L 3$ & 79 & 95 & 0.0019 & 0.213 & $0.079-0.569$ \\
\hline $2 D S 4$ & 96 & 91 & NS & & \\
\hline $2 D L 2$ & 70 & 45 & 0.0004 & 2.819 & $1.582-5.026$ \\
\hline $2 D L 5$ & 47 & 55 & NS & & \\
\hline $3 D S 1$ & 37 & 44 & NS & & \\
\hline $2 D S 1$ & 41 & 44 & NS & & \\
\hline $2 D S 2$ & 55 & 41 & 0.0487 & 1.750 & $1.001-3.054$ \\
\hline $2 D S 3$ & 19 & 21 & NS & & \\
\hline $2 D S 5$ & 36 & 42 & NS & & \\
\hline $2 D L 4$ & 100 & 100 & NS & & \\
\hline $3 D L 2$ & 100 & 99 & NS & & \\
\hline $3 D L 3$ & 100 & 100 & NS & & \\
\hline $2 D P 1$ & 97 & 98 & NS & & \\
\hline $3 D P 1$ & 100 & 100 & NS & & \\
\hline
\end{tabular}

Significant differences between RA patients and HS are in bold; CI: Confidence Interval; NS: Not Significant.

Table 3

Frequency of KIR genotypes groups AA and BX in RA patients and HS

\begin{tabular}{|c|c|c|c|c|c|}
\hline $\begin{array}{l}\text { KIR } \\
\text { Genotypes }\end{array}$ & $\begin{array}{c}\mathrm{RA}(n=100) \\
\%\end{array}$ & $\begin{array}{c}\mathrm{HS}(n=100) \\
\%\end{array}$ & $p$ & $O R$ & $95 \% \mathrm{CI}$ \\
\hline Group AA & 19 & 34 & 0.0171 & 0.461 & $0.242-0.877$ \\
\hline Group BX & 81 & 66 & 0.0171 & 2.168 & $1.140-4.124$ \\
\hline
\end{tabular}

Significant differences between RA patients and controls are in bold; CI: Confidence Interval.

in HS ( $p=0.0001, O R=0.248)$. It also identified four new genotypes: G35, G36, G37 and G38, not yet registered by allele Frequency Database Net [13], two in HS and two in RA patients. The representation of the 38 genotypes and their frequencies are shown in Table 4.

\section{Discussion}

This study allowed us to identify genes and genotypes KIR associated with RA, which suggest them as genetic factors of protection or susceptibility to disease. Moreover, our results suggest that KIR2DL2, KIR2DL3 and KIR2DS2 genes have immunological implications, they share the same set of ligands HLA-C1 and the KIR expressing cells: CD28null T-cells and NK cells are present in patients with RA $[8,9,14]$. Below we discuss the possible immunological involvement of these genetic factors associated with RA.

Gene KIR2DL3 has frequency significantly decreased in RA, this suggests that the absence of this gene may be associated with susceptibility to develop RA. This gene encodes a receptor inhibitor, KIR2DL3, of intracellular signaling which contributes the blockade of cytotoxic function $[7,20]$ and secretion of cy- tokines such as IFN- $\gamma$ important in RA autoreactivity $[20,21]$. In this context, KIR2DL3 gene could play a protector role against disease.

The KIR2DS2 gene also showed association with RA, suggesting it as a susceptibility factor to disease. Codes for the receptor KIR2DS2 associated noncovalently with the adapter molecule DAP-12 (which contains domains ITAM) [12], which allows it to activate intracellular signaling in NK cell. Moreover, can act as a co-stimulatory molecule in CD28null T-cells increasing activation by $\mathrm{T}$ cell receptor (TCR) [14]. These two functions of the receptor trigger increased IFN- $\gamma$ secretion and release of granzyme and perforin, contributing to the destruction joints in RA patients [10]. This possibly represents the immune impact of $K I R 2 D S 2$ in the disease.

The KIR2DL2 gene frequency was higher in RA patients, suggesting it may have a role as a susceptibility factor to disease. KIR2DL2 encodes a receptor inhibitor with stronger affinity for ligand HLA-C1 that KIR2DL3 [22]. Its role as inhibitor of intracellular signaling could be blocked in RA patients by two hypothetical mechanisms: the first reported in the study by Fadda et al. [22] where differences in the sequence of peptides contents in HLA class I molecules can regulate the activity of $\mathrm{NK}$ cell antagonizing inhibition 
Table 4

The 38 KIR genotypes identified and their frequency in RA patients and HS

\begin{tabular}{|c|c|c|c|c|c|c|c|c|c|c|c|c|c|c|c|c|c|c|c|c|c|c|c|}
\hline \multicolumn{3}{|c|}{ Genotype } & \multicolumn{16}{|c|}{$K I R$ genes } & \multirow{2}{*}{$\begin{array}{c}\text { RA } \\
n=100 \\
\%\end{array}$} & \multirow{2}{*}{$\begin{array}{c}\text { HS } \\
\begin{array}{c}n=100 \\
\%\end{array}\end{array}$} & \multirow[b]{2}{*}{$p$} & \multirow[b]{2}{*}{$O R$} & \multirow[b]{2}{*}{$95 \% \mathrm{Cl}$} \\
\hline Group & G & ID $^{*}$ & స్లె & ลี & ลี่ & $\begin{array}{l}\text { జे } \\
\text { ลิ }\end{array}$ & ลี่ & ลี & ळ్లి & ฉิ & ญิ & ณิ & ณิ & ปี่ & ธี่ & D्ల & ฐั & ఏ్ల & & & & & \\
\hline$\overline{\mathrm{AA}}$ & G1 & 1 & & & & & & & & & & & & & & & & & 11 & 34 & 0.0001 & 0.248 & $0.118-0.519$ \\
\hline AA & $\mathrm{G} 2$ & 180 & & & & & & & & & & & & & & & & & 7 & 0 & NS & & \\
\hline AA & G3 & 195 & & & & & & & & & & & & & & & & & 1 & 0 & NS & & \\
\hline $\mathrm{BX}$ & G4 & 2 & & & & & & & & & & & & & & & & & 8 & 9 & NS & & \\
\hline $\mathrm{BX}$ & G5 & 3 & & & & & & & & & & & & & & & & & 9 & 9 & NS & & \\
\hline $\mathrm{BX}$ & G6 & 4 & & & & & & & & & & & & & & & & & 18 & 7 & 0.0208 & 2.796 & $1.138-6.866$ \\
\hline $\mathrm{BX}$ & G7 & 5 & & & & & & & & & & & & & & & & & 6 & 7 & NS & & \\
\hline $\mathrm{BX}$ & G8 & 6 & & & & & & & & & & & & & & & & & 3 & 6 & NS & & \\
\hline $\mathrm{BX}$ & G9 & 7 & & & & & & & & & & & & & & & & & 2 & 0 & NS & & \\
\hline $\mathrm{BX}$ & $\mathrm{G} 10$ & 8 & & & & & & & & & & & & & & & & & 0 & 2 & NS & & \\
\hline BX & G11 & 9 & & & & & & & & & & & & & & & & & 2 & 1 & NS & & \\
\hline $\mathrm{BX}$ & $\mathrm{G} 12$ & 12 & & & & & & & & & & & & & & & & & 0 & 1 & NS & & \\
\hline $\mathrm{BX}$ & $\mathrm{G} 13$ & 18 & & & & & & & & & & & & & & & & & 5 & 2 & NS & & \\
\hline $\mathrm{BX}$ & G14 & 19 & & & & & & & & & & & & & & & & & 9 & 1 & 0.0300 & 6.887 & $1.203-39.45$ \\
\hline $\mathrm{BX}$ & $\mathrm{G} 15$ & 27 & & & & & & & & & & & & & & & & & 0 & 1 & NS & & \\
\hline $\mathrm{BX}$ & G16 & 33 & & & & & & & & & & & & & & & & & 0 & 1 & NS & & \\
\hline $\mathrm{BX}$ & G17 & 44 & & & & & & & & & & & & & & & & & 0 & 1 & NS & & \\
\hline $\mathrm{BX}$ & $\mathrm{G} 18$ & 46 & & & & & & & & & & & & & & & & & 0 & 1 & NS & & \\
\hline $\mathrm{BX}$ & G19 & 68 & & & & & & & & & & & & & & & & & 0 & 1 & NS & & \\
\hline $\mathrm{BX}$ & $\mathrm{G} 20$ & 69 & & & & & & & & & & & & & & & & & 1 & 5 & NS & & \\
\hline $\mathrm{BX}$ & G21 & 70 & & & & & & & & & & & & & & & & & 0 & 1 & NS & & \\
\hline $\mathrm{BX}$ & $\mathrm{G} 22$ & 71 & & & & & & & & & & & & & & & & & 2 & 1 & NS & & \\
\hline $\mathrm{BX}$ & $\mathrm{G} 23$ & 72 & & & & & & & & & & & & & & & & & 3 & 1 & NS & & \\
\hline$B X$ & G24 & 73 & & & & & & & & & & & & & & & & & 2 & 2 & NS & & \\
\hline $\mathrm{BX}$ & G25 & 80 & & & & & & & & & & & & & & & & & 0 & 1 & NS & & \\
\hline $\mathrm{BX}$ & G26 & 90 & & & & & & & & & & & & & & & & & 2 & 1 & NS & & \\
\hline BX & $\mathrm{G} 27$ & 118 & & & & & & & & & & & & & & & & & 1 & 0 & NS & & \\
\hline BX & G28 & 192 & & & & & & & & & & & & & & & & & 1 & 0 & NS & & \\
\hline $\mathrm{BX}$ & G29 & 200 & & & & & & & & & & & & & & & & & 0 & 1 & NS & & \\
\hline $\mathrm{BX}$ & G30 & 243 & & & & & & & & & & & & & & & & & 1 & 0 & NS & & \\
\hline BX & G31 & 269 & & & & & & & & & & & & & & & & & 1 & 0 & NS & & \\
\hline $\mathrm{BX}$ & G32 & 344 & & & & & & & & & & & & & & & & & 1 & 0 & NS & & \\
\hline $\mathrm{BX}$ & G33 & 394 & & & & & & & & & & & & & & & & & 2 & 0 & NS & & \\
\hline$B X$ & G34 & 413 & & & & & & & & & & & & & & & E & & 0 & 1 & NS & & \\
\hline $\mathrm{BX}$ & G35 & NAS1 & & & & & & & & & & & & & & & & & 1 & 0 & NS & & \\
\hline $\mathrm{BX}$ & G36 & NAS2 & & & & & & & & & & & & & & & & & 1 & 0 & NS & & \\
\hline BX & G37 & NAS3 & & & & & & & & & & & & & & & & & 0 & 1 & NS & & \\
\hline $\mathrm{BX}$ & G38 & NAS4 & & & & & & & & & & & & & 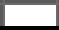 & & & & 0 & 1 & NS & & \\
\hline
\end{tabular}

mediated by KIR2DL2 favoring activation by its counterpart KIR2DS2; and the second reported by Matsui et al. [23] where antibodies to KIR2DL2 are found in $30 \%$ of RA patients and probably are involved in the breakdown of self tolerance.

The evidence found in our study of the genes $K I R 2 D S 2$ and KIR2DL2 as possible genetic susceptibility factors: is also seen in the western European and Polish populations studied by Yen et al. for KIR2DS2 [10]; and in the study of Majorczyk et al. [15], where both genes KIR2DS2 and KIR2DL2 were found associated with RA in patients with extra-joins manifestations. Conversely in Caucasian population from northern Ireland, Middleton et al. not found association of these genes $K I R$ with RA [24].

On the other hand, when we analyzed by group genotypes AA or BX, the frequency of the BX group was increased in patients with RA compared with HS. These $\mathrm{BX}$ genotypes are those containing activators genes (as KIR2DS2) which could contribute significantly to the intracellular signaling (dependent ligands HLA class I) $[7,25]$ and activate cytotoxic function and secretion of cytokines $[12,20]$ and thus favors to the pathology.
However, when we analyzed the individual genotypes, the G6 genotype (BX) showed association with RA, suggesting it as a susceptibility factor. This genotype contains KIR2DL2/2DS2 genes, which were reported by McGeough et al. [26], more frequently in patients who respond to therapy with anti-TNF- $\alpha$. In our study did not consider the treatment, making it possible to focus future studies into the response to treatment in patients with this genotype.

The frequency of the genotype G14 in RA patients was augmented. This suggests the genotype G14 as a susceptibility factor to disease. It is interesting to highlight that in RA patients with genotype G14, the only activator gene is KIR2DS4, it could be play an important role in the immunopathogenesis of RA. Yen et al. [16] found association of KIR2DS4 gene with RA patients in Taiwanese population; however we not found association of frequency of KIR2DS4 with RA. On other hand, has been reported that function inhibitory of KIR2L2 is blocked by autoantibodies [22,23] in RA patients. This situation could be present in patients with genotype G14, favoring the activation by KIR2DS4 gene. 
The frequency of genotype G1 was increased significantly in HS and this genotype present KIR2DL3 gene. This gene show association as protection factor to RA, this fact appears to be only when KIR2DS2 and $K I R 2 D L 2$ are absent (genes associated with RA), like in this genotype $\mathrm{G} 1$, but when KIR2DL3 is present in the same genotype with KIR2DL2 (G14) or both $K I R 2 D L 2$ and KIR2DS2 (G6) genes, seem to have no effect.

We analyzed the genotypes considering the absence or presence of genes that had shown significant differences: KIR $2 D L 3 / 2 D L 2 / 2 D S 2$. Interestingly there are two genotypes (G2 and G33) with none of these genes, corresponding to 9 individuals in the RA group while in HS we found none $(p=0.0095, O R=20.87,95 \%$ $\mathrm{CI}=1.198-363.6)$. It is noteworthy that only 27 individuals have been reported for 8 genotypes, with this feature, in different populations around the world [13], but none of these individuals are patients with RA. So it would be important to investigate whether this feature is unique to our population and can be used as a genetic marker for susceptibility to this disease.

We can conclude that this study of KIR genes, allowed suggest genetics factors for susceptibility and protection against RA in population of western of Mexico. This work provides a rationale to realize genetics and functional studies, in which it would be interesting to do an analysis on subgroups of patients with RA since particular clinical manifestation of RA may have different genetic background with respect to KIR genotype.

\section{Conflicts of interest}

The authors have declared no conflicts of interest.

\section{References}

[1] Scott DL, et al., Rheumatoid arthritis, Lancet Seminar, 2010; 376: 1094-1108.

[2] McInnes IB and Schett G, Cytokines in the pathogenesis of rheumatoid arthritis, Nature, 2007; 7: 429-442.

[3] Tobón GJ, et al., The environment, geo-epidemiology, and autoimmune disease: Rheumatoid arthritis, Journal of Autoimmunity, 2010; 35: 10-14.

[4] Orozco G, et al., Genetic basis of rheumatoid arthritis, Biomedicine and Pharmacotherapy, 2006; 60: 656-662.

[5] Gregersen PK, Susceptibility Genes for Rheumatoid Arthritis, Bulletin of the NYU Hospital for Joint Diseases, 2010; 68(3): 179-182.

[6] Gourraud P-A, et al., Linkage disequilibrium organization of the human KIR superlocus: Implications for KIR data analyses, Immunogenetics, 2010; 62: 729-740.
[7] Rajalingam R., Human diversity of killer cell immunoglobulin-like receptors and disease, The Korean Journal of Hematology, 2011; 46(4): 216-228.

[8] Fasth AER, et al., Activating NK-cell receptors co-stimulate CD4+CD28- T cells in patients with rheumatoid arthritis, $E u$ ropean Journal of Immunology, 2010; 40: 378-387.

[9] Dalbeth N and Callan MFC, A Subset of Natural Killer Cells Is Greatly Expanded Within Inflamed Joints, Arthritis and Rheumatism, 2002; 46(7): 1763-1772.

[10] Yen J-H, et al., Major Histocompatibility Complex Class I recognizing Receptors Are Disease Risk Genes in Rheumatoid Arthritis, Journal of Experimental Medicine, 2001; 193(10): 1159-1167.

[11] Middleton D and Gonzelez F, The extensive polymorphism of KIR genes, Immunology, 2009; 129: 8-19.

[12] Williams AP, et al., Hanging in the balance: KIR and their role in disease, Molecular interventions, 2005; 5(4): 226-240.

[13] Gonzalez FF, et al., Allele frequency net: A database and online repository for immune gene frequencies in worldwide populations, Nucleic Acid Research, 2011(39): D913-D919.

[14] Namekawa T, et al., Killer Cell activating receptors function as costimulatory molecules on CD4+CD8null T cells clonally expanded in Rheumatoid Arthritis, The Journal of Immunology, 2000; 165: 1138-1145.

[15] Majorczyk E, et al., Associations of killer cell immunoglobulin-like receptor genes with complications of rheumatoid arthritis, Genes and Immunity, 2007; 8: 678-683.

[16] Yen J-H, et al., Killer cell immunoglobulin-like receptor gene's repertoire in rheumatoid arthritis, Scandinavian Journal of Rheumatology, 2006; 35: 124-127.

[17] Aletaha D, et al., 2010 Rheumatoid Arthritis Classification Criteria, Arthritis and Rheumatism, 2010; 62(9): 2569-2581.

[18] Miller SA, et al., A simple salting out procedure for extracting DNA from human nucleated cells, Nucleic Acids Research, 1988; 16(3): 1215

[19] Vilches C, et al., Facilitation of KIR genotyping by a PCR-SSP method that amplifies short DNA fragments, Tissue Antigens, 2007; 70: 415-422.

[20] Rajagopalan S and Long EO, Understanding how combinations of HLA and KIR genes influence disease, Journal Experimental Medicine, 2005; 201(7): 1025-1029.

[21] Flodström-Tullberg M, et al., Natural killer cells in human autoimmunity, Current Opinion in Immunology, 2009; 21: 634-640.

[22] Fadda L, et al., Peptide antagonism as a mechanism for NK cell activation, Proceedings of the National Academy of Sciences. USA 107: 10160-10165.

[23] Matsui T, et al., Detection of Autoantibodies to Killer Immunoglobulin-Like Receptors Using Recombinant Fusion Proteins for Two Killer Immunoglobulin-Like Receptors in Patients With Systemic Autoimmune Diseases, Arthritis and Rheumatism, 2001; 44(2): 384-388.

[24] Middleton D, et al., No association in frequency of KIR receptors in patients with rheumatoid arthritis from Northern Ireland, Tissue Antigens, 2007; 69: 577-582.

[25] Nelson, GW, et al. Heterozygote advantage in autoimmune disease: Hierarchy of protection/susceptibility conferred by HLA and killer Ig-like receptor combinations in psoriatic arthritis, Journal of Immunology, 2004; 173: 4273-4276.

[26] McGeough CM, et al., Killer immunoglobulin-like receptor and human leukocyte antigen-C genotypes in rheumatoid arthritis primary responders and non-responders to anti-TNF-a therapy, Rheumatology International, 2011: 1838-1846. 


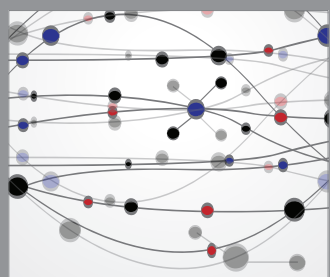

The Scientific World Journal
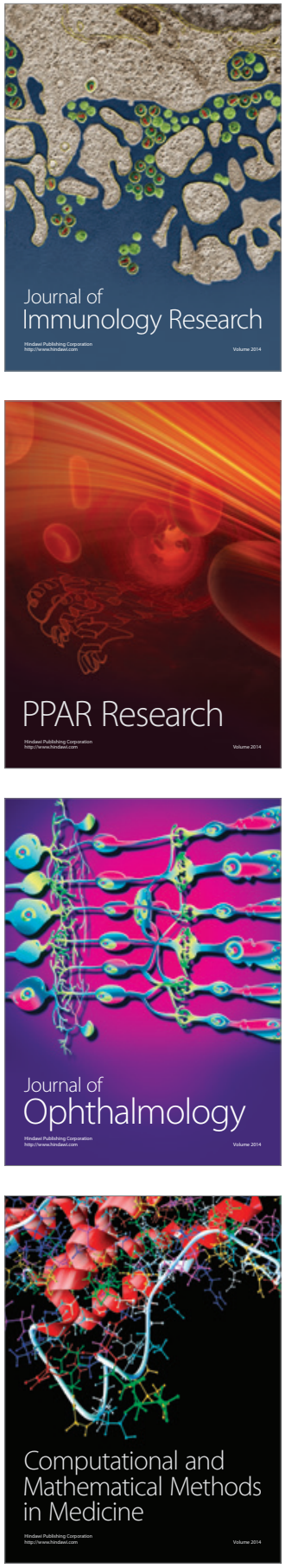

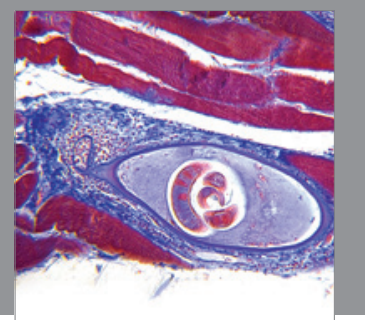

Gastroenterology

Research and Practice
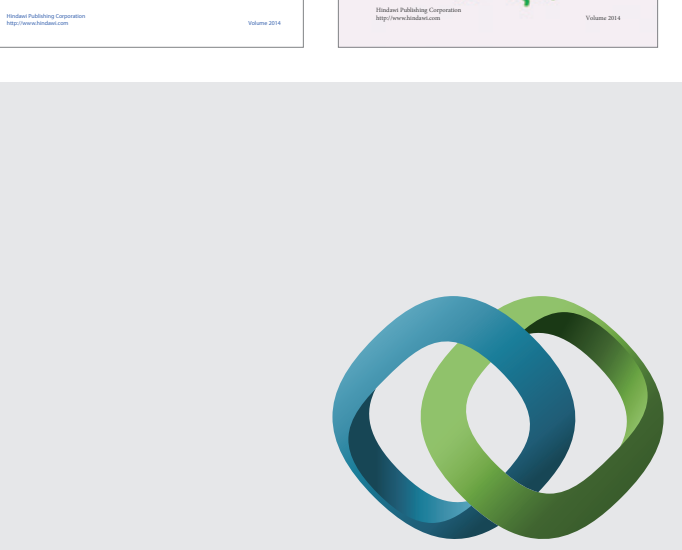

\section{Hindawi}

Submit your manuscripts at

http://www.hindawi.com
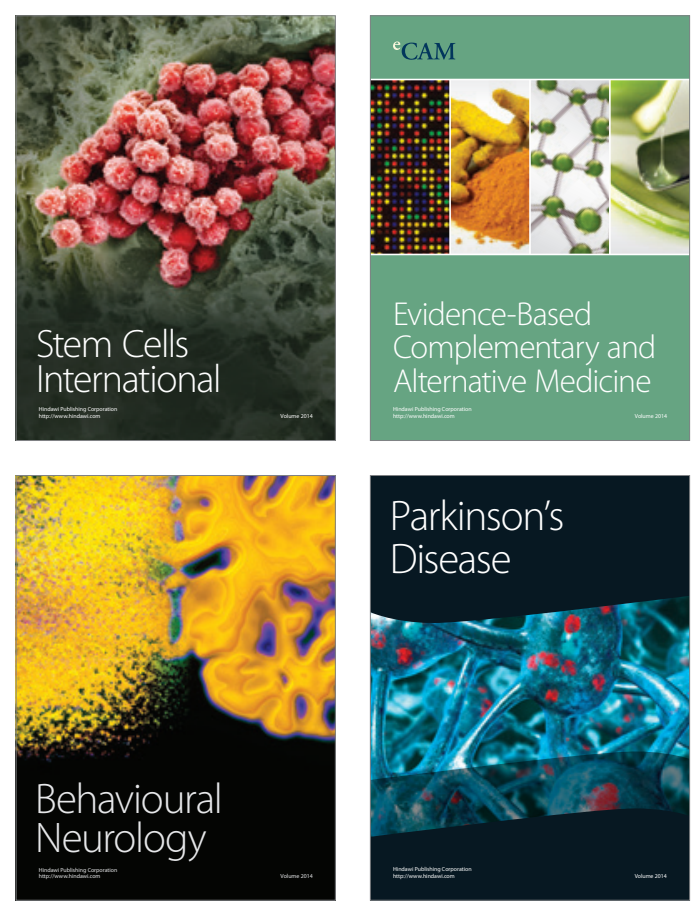

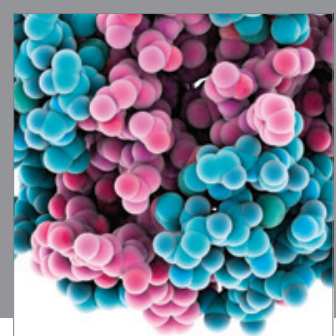

Journal of
Diabetes Research

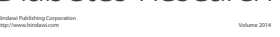

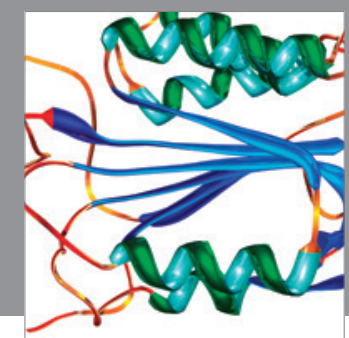

Disease Markers
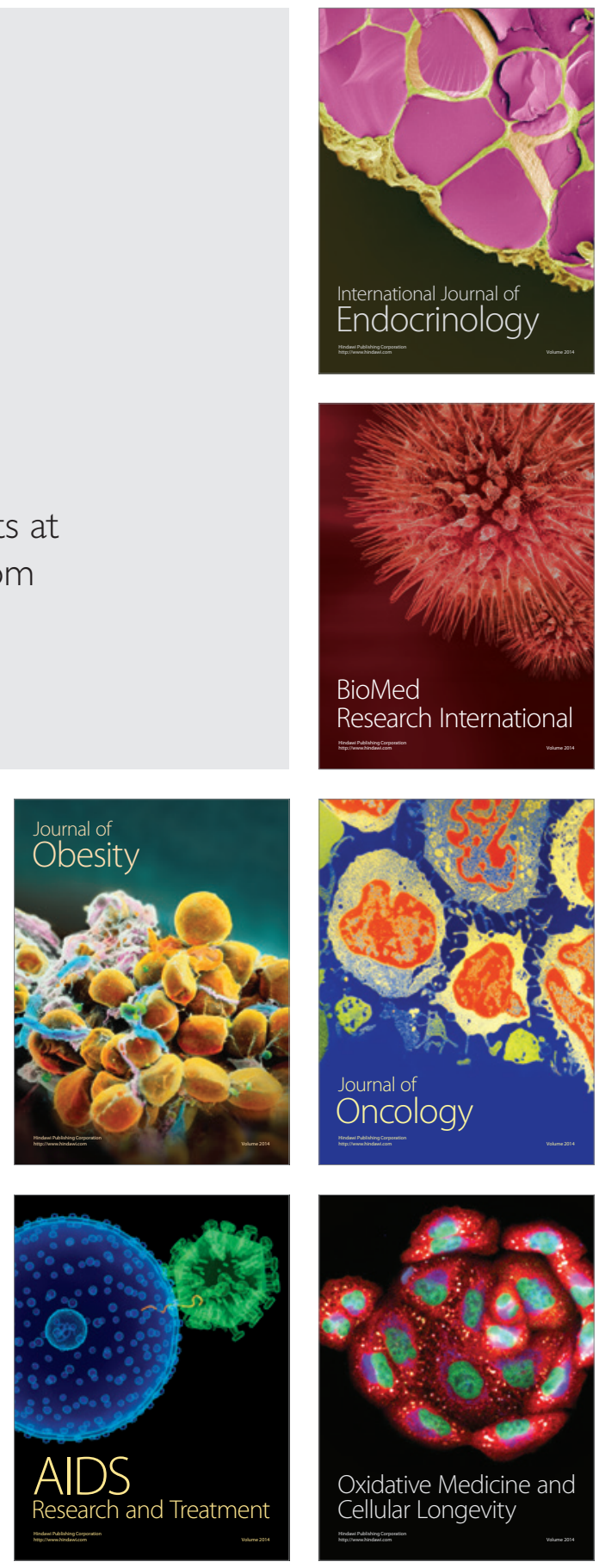